\title{
Theoretical and Methodological Approaches to the Study of the Phenomenon of Aggression
}

\author{
Anton Vladimirovich Serikov ${ }^{1}$, Darya Nikolaevna Stukalova ${ }^{1}$ \& Victor Vladimirovich Chernous ${ }^{1}$ \\ ${ }^{1}$ Southern Federal University, Russia \\ Correspondence: Anton Vladimirovich Serikov, Southern Federal University, Pushkinskaya st. 160, 344007, \\ Rostov-on-Don, Russia.
}

Received: November 1, 2014

Accepted: December 23, 2014 Online Published: March 16, 2015

doi:10.5539/ass.v11n 7 p227

URL: http://dx.doi.org/10.5539/ass.v11n7p227

\begin{abstract}
The article is concerned with the research of the social causes of aggression. The author compares various theoretical approaches to the analysis of the causes of aggressive behavior.

The article substantiates the necessity to develop a systematic approach to the problem of aggression and is explored from the point of sociology view.
\end{abstract}

Keywords: aggressiveness, destructiveness, theories of human's aggressiveness

\section{Introduction}

The crisis phenomena in the society, accompanied by as transformation of a public consciousness inevitably lead to changes in people's behavior. Forms of restructuring of individual consciousness and behavior are very various, but, unfortunately, they are mostly accompanied by aggression increase. This fact can be observed both in the official statistical reports on the dynamics of crime and in everyday life and activities. The problem of aggressive behavior is particularly important in terms of global financial crisis, followed by a change in the socio-economic and psychological well-being of people (Serikov, 2013).

Each year analytical company Economist Intelligence Unit publishes rating of peaceful and calm life of citizens (Global Peace Index). Russia is $152^{\text {th }}$ in the rating. Also in the "worst" top ten are: Nigeria, Colombia, Pakistan, Lebanon, Ivory Coast and Angola.

Table 1.

\begin{tabular}{ccc}
\hline$\#$ & Country & Score \\
\hline 1 & Iceland & 1.189 \\
2 & Denmark & 1.193 \\
3 & Austria & 1.200 \\
4 & New Zealand & 1.236 \\
5 & Switzerland & 1.258 \\
6 & Finland & 1.297 \\
7 & Canada & 1.306 \\
8 & Japan & 1.316 \\
9 & Belgium & 1.354 \\
10 & Norway & 1.371 \\
152 & Russia & 3.039 \\
\hline
\end{tabular}

Thus, the problem of aggression in the sociology has both theoretical and socio-practical significance (Agapov, 2002).

\section{Method}

Contemporary stage of mankind's development requires a synthesis of the old and development of new theoretical and methodological as well as conceptual foundations of aggression research. In recent years, a wealth factual material in the field of biology, ethnology, psychology, sociology, anthropology and ethnography 
was accumulated. Despite this, there is an objective need to develop a systematic approach to the problem of aggression, aggressiveness and destructiveness. In addition it is necessary to examine more carefully the phenomenon of aggression from the perspective of social science. Several key points of growth (psychoanalytic tradition, social-psychological theories of aggression, ethology, etc) can be pointed out in the history of the aggression problem research. Sigmund Freud's and Konrad Lorenz's creation initiated formulation and possible interpretations of the aggression problem in its modern form, and also became a methodological and conceptual basis for all subsequent various theories of aggression. A number of fundamental theoretical concepts of aggression and the corresponding categorical construct were formed in the process of numerous studies then. Such foreign scientists as A. Bandura, L. Berkowitz, R. Baron, R. Geen, E. Donnerstein, K. Lorenz, C. Moyer, D. Richardson, J. P. Scott, A. Storr, S. Feshback etc. made a great contribution to the aggression research.

\section{Results}

\subsection{The Origin of Theories of the Nature of Aggression}

In order to offer the approach to aggression research, it is necessary to examine carefully the main theoretical approaches to the study of aggression. Konrad Lorenz was the founder of the theory of instinctive behavior. He expounded his views on aggression in his paper "Das sogenannte Böse. Zur Naturgeschichte der Aggression", published in 1963, and then translated in English under the title "On Aggression" in 1966. K. Lorenz defines aggression as "a human or animal instinct of struggle directed against fellows" (Lorenz, 1998). K. Lorenz dwelled on a description only biosocial nature of aggression, not taking into account the social determinancy of aggressive human behavior.

Classical and modern theories of frustration-aggression relate to identifying a specific aggressive motive as an impulse directed at causing of harm to other individuals or inanimate objects. There are several variants of these theories in historical sociological tradition, the main representatives are: L. Berkowitz, R. Geen, E. Donnerstein, S. Feshback and others. Originated in the late 30 's-early 40 's as a part of the formulated classical hypothesis about frustration-aggression, according to which aggression is always based on frustration and frustration always leads to aggression, frustration-aggression hypothesis initiated intensive experimental studies of the human aggression phenomenon (Dollard, Miller, Mowrer, \& Sears, 1939).

Ruth Benedict, the representative of the ethno-psychological concept in ethnology, examines patterns of different ethnic groups' behavior and character in her works "Psychological Types in the Cultures of South-West", "Configuration of Cultures in North America", "Patterns of Culture". Depending on the availability of aggressive behavior Ruth Benedict distinguishes 3 types of cultural configurations (Apollonian, Dionysian and Paranoid) (Benedict, 1932). The Dionysian is the most aggressive type, focused on individualism. There are frequent manifestations of public forms of violence, those who proved himself as fearless and aggressive, not hesitating to violent achievement of goals are highly prestigious in the society. Benedict was the first who put the level of aggression and violence in the foundation of social skills.

\subsection{Psychological Approaches to the Study of Aggression}

Sigmund Freud made a decisive turn in the study of aggression problem in 1920, when he published his Paper "Beyond the Pleasure Principle". Now next to the sexual attraction is independent destructive - "death instinct". At first, destructive drive is internal- directed against the psyche, then it is directed to the outworld and acts as an aggression. In case of outwardly directed aggression suppression, it accumulates around the "Super-Ego" that leads to a morbid sense of guilt, unreasonable fear, neurosis, persecution mania and even to a suicide. Freud suggested that the less aggressive spills out in destructive acts, the greater is pressure on the individual psyche, the more likely this drive will break through all barriers and spill over into acts of amotivational violence. Inasmuch as aggressiveness belongs to human nature, no social reforms can curb the violence. There is an eternal struggle between the instinct of life, Eros, uniting living beings in an increasingly complex union, and Thanatos, "death instinct" and instinct of destruction (Freud, 2010). From the point of view of Freudianism, aggressiveness is rightfully considered as a form of sublimation of the death instinct - i.e. it is congenital. Freud considered aggression as a response to any kind of frustration. For many years he was interested in the problem of aggression against yourself. According to Freud, there is a mechanism of neutralization of an internal aggression, which is the main function of the Ego. But the Ego does not appear along with the birth of a child, it is formed along with a process of child's development. Together with the Ego formation the mechanism of neutralization of aggression begins to develop. At first Freud used the terms "aggressive" and "active" as synonyms, considering that aggression transforms into activity under normal personality development (Freud, 2010). 
Most authors of psychoanalytic tradition - C. Jung, W. Reich, K. Horney, H. S., Sullivan, H. Marcuse, A. Mitscherlich and others raised the problem of aggression and destructiveness. But this problem was considered only along with other issues, and was not distinguished as a separate or a special subject. An experience of social and cultural psychoanalysis (which is commonly called neo-Freudianism in the history of sociology) is interesting. Horney, Sullivan, Fromm rejected instinctive and libidinal theories of aggression. The consideration of social and cultural factors is much more important for understanding of human nature rather than reviewing biological factors. The originality of the approach is the connection of social-psychological, philosophicalantropological and socio-historical analysis in interpretation of the phenomenon of aggression. The main feature of the considered concepts is, on the one hand, rejection of interpretation of aggression as a primary biological instinct, and, on the other hand - consideration of this phenomenon as a kind of derivation formation, the result of the secondary distortion of a real human nature, i.e. as a product of culture and combination of social factors (Fromm, 1992).

The problem of aggression is considered in details by Erich Fromm in "the Anatomy of Human Destructiveness". Fromm describes in detail the relevance of the phenomenon of aggression research- "I began studying aggression and destructiveness not only because they are among the most important theoretical problems of psychoanalysis, but also because destructiveness wave, having swept the world today, gives a reason to believe that such a study will have important practical value" (Fromm, 1992).

According to E. Fromm, a man is psychologically cultural only to the extent that he is able to control natural origin in himself. If control mechanisms are weakened, a person is prone to have symptoms of malignant aggression, and destructiveness and cruelty can be considered as synonyms of this aggression. The man appeared in the animal world as extremely aggressive. Man differs from animals precisely because he is a murderer. He is the only representative of primates, who torture and kill his tribesman without biological and economic reasons and take pleasure in it (Fromm, 1992).

According to the researcher, equally wrong are those who find the origins of aggression only in biological instincts, and those who deny the importance of these instincts and interpret a man as a puppet of a social environment. The scientist believes that aggression is a quite complicated phenomenon, which components have different genetic origin and different causation (Agapov, 2013).

E. Fromm distinguishes two types of aggression. The first type is common both for humans and animals, it is phylogenetically originated impulse to attack or escape depending on the situation, when there is a threat to life. This defensive, "benign" aggression is for a survival of an individual or generation; it has biological forms of appearance and fades as soon as danger disappears. Another kind of aggression is "malignant aggression disruptiveness or cruelty, peculiar only to man and almost alien for other mammals; it does not serve biological adaptation and does not have, therefore, any particular purpose. And the degree of destructiveness increases with the progress of civilization (not vice versa). Modern civilization creates vast mass of alienated people. All spheres of human activity are mechanized and destroyed. Modern industrial society is oriented almost only on "simple incentives: sex, hoarding, sadism, narcissism, destructiveness" (Fromm, 1992).

\subsection{Sociological Approaches to the Study of Aggression}

Since the mid 70's the approach to understanding the nature of human aggression - the theory of social determinism (learning) of aggression appeared in social thought. The basic principles of the approach have been developed in the framework of neobehaviorism research paradigm (Zilmann \& Zimbardo). Thus, Daniel Zillmann in the framework of this concept denies that aggression is an instinct, he argues that it performs its instrumental function and may even be beneficial (Bandura, 2001). And Philip Zimbardo conducts his famous Stanford Prison Experiment in the confirmation of the existence of the social bases of aggressive behavior (Zillmann, 1971).

The most prominent exponent of this paradigm is American scientist A. Bandura. Bandura considers an aggression as a specific form of an individual social behavior, obtained and supported by all conditions of its social environment. The theory of social determinism of aggression is an attempt to a serious and comprehensive understanding of the basic mechanisms of formation, maintenance and regulation of human aggression (Zimbardo, 1973).

The theory of social explanation of aggression is purely sociological model. Its authors are M. Billig and R. Dobash. They shifted the emphasis from the description of psychological motivation and other subjective predispositions of the individual to specific structures of modern society. An extreme sociologisation of the variety of factors that are included in the concept of aggression determinant is opposite to instinctivism (Billing, 1976). 
Research and development of the group of American researchers, among which are: J. Tedeschi, R. Smith, R. Brown and others are very important. Researchers developed a theory of social influence to describe and explain actions usually associated with human aggression. A new approach - the use of the conception "coercive force". The most prominent exponent of this interpretation of aggression is J. Tedeschi. Scientists radically reconsider the status of the concept "aggression", regarding aggression as not any one specific kind of human action attribute but a kind of social symbol used to define those actions where the principal means of social influence is coercive force (Tedeschi, 1983).

Forms and manifestations of violence and aggression in youth environment are studied in the framework of Chicago school's social thought and sociology of deviant behavior. For example, a Mexican sociologist Castillo Berthier Hector explores the role of violence and aggression in the formation of youth urban culture. American sociologist $\mathrm{Ch}$. Bedwell wrote about similar phenomenon: "the task of the young people, usually assigned by parents and acutely perceived, is to succeed in any profession, which social rank is equivalent to the full extent to the father's profession social rank" (American sociology, 1972). When traditional structures do not allow to realize achievement need, which A. Schutz called "life activism", people are looking for new ways, hence the desire to get a higher status through deviant social practice (Schutz, 1953). "Of course, in all countries emphasized S. Lipset, the reality usually does not conform to the principles, and young people, especially those who have been spoiled in adolescence, feel it acutely. Therefore, a disproportionately great part of the educated young people tend to support the idealistic movements that accept the adult world ideology more seriously than the very adult world" (Lipset \& Rokkan, 1967).

Mass media play a very important role in the formation of aggressive youth, American sociologist Chr. Lasch wrote in the book "The Revolt of the Elites and the Betrayal of Democracy" that "TV, by reason of poverty, becomes the main nurse for a child... [Children] are being exposed to it in the rough, but attractive way, which represents market values on an understandable simplest language. Commercial TV clearly reflects the cynicism, which is always implied by the market ideology" the most unambiguous way (Lasch, 1996).

\section{Discussions}

Analyzing all these theories it can be concluded that the various theories of aggression reveal the multidimensionality and diversity of aggression, multiple-factor conditionality of aggression as a behavioural act and aggressiveness as a personality trait. The historical evolution of personal theories of aggression is characterized by a tendency of gradual substitution of explanatory models of biological type for models of socio-psychological and sociological nature. The ultimate biologisation, psychologisation and sociologisation of the variety of factors that are included in the concept of aggression determinant are an extreme in the study of the problem. The process of individual and social development is very complex and it depends on many components: heredity, environment, culture, upbringing, etc.

Processes of social crisis in modern society adversely affect the psychology of people, cause an anxiety and tension, exacerbation, cruelty and violence. The financial crisis and the ensuing social and economic processes have led our society to serious difficulties and internal conflicts, to a significant increase in the prevalence and diversity of immoral behavior forms, crime and other deviant behavior. Statistically, there is a growth of deviant behaviour among people of different social and demographic groups.

Aggression, violence and conflict are the most serious problems of modern society. A man is a very aggressive creature, the child demonstrates the first signs of aggression long before he learn to talk. Aggressiveness submits its own very peculiar and sometimes unpredictable laws. These laws affect not only the behavior of each person, including politicians and military, but also the behavior of the society and the state as a whole.

From the point of view of sociology, the influence of groups and society as a whole on the individual aggressiveness, obviously, are of the greatest interest. It is evident that there are a number of social groups, in which the increased aggressiveness is more than just an approved personal characteristic that allows an individual to occupy a high status position in informal community structure, but, in fact, a necessary condition for physical survival. To date, there is every reason to confirm that aggressiveness can spread through social contagion and take a form of a mass phenomenon under certain conditions. Asocial youth groups - football fans, skinheads, etc. are obvious examples of that (Serikov, 2009). An extreme social danger of such mass aggressiveness is evident, however, much more local manifestations of aggression in the group context are often destructive. Even in the areas where aggressiveness, as already mentioned, is justified and expediential, in general, its excessive manifestation destroy interaction in a group and prevent an achievement of a common goal. 
The main sources of aggressive behavior and youth extremism in Russia are primarily socio-political factors: the crisis of socio-political and economic systems; socio-cultural deficit and criminalization of mass culture; the expansion of social manifestations of the "escape from life"; the lack of alternatives of leisure activities; the crisis of school and family education. All this suggests that the main problems we have to deal with young people in Russia lies in the sphere of conflict, primarily in the family and in relationships with coevals.

Modern society exists in the information era, people do not imagine their existence without the information which helps them to find themselves in life and survive. The problem is that the information that people obtain can be not only constructive but also it can influence destructive on the conscious mind, the subconscious and, as a result, the behavior of people. Mass media is one of the main channels that transmit information to a society, which seek to elucidate the maximum possible number of phenomena of reality, including violence and aggression (Box, 1983).

Violence and aggression can act both as individual characteristics, consisting in indifference to suffering of others or in pursuit of their infliction, and as conscious actions of the infliction of suffering, excruciations for others to achieve specific external goals or satisfaction. Unintentional incautious actions (or when a man does not aware of an activity for one or another reason), even with the most severe consequences are not terrible. Thus, the nature of violence is determined by the intentions of the subject, when the infliction of suffering is the motive or purpose of the behavior. Aggression and violence as personality traits are mainly formed in childhood and adolescence, in the early stages of socialization.

\section{Summary}

The critical state of society, its political and economic structures, the symbolic destruction of the world, which is the characteristic of the Soviet type of socialization, lack of holistic ideas of new upbringing has led to the frustration of all socio-demographic groups. But especially disoriented are young people who are looking for clear and attractive ideals, but does not find them that contributes to the growth of social aggression. Also noteworthy is the fact that social disorganization (the state of society, when cultural values, norms and social interactions are absent, weaken or contradict one another), is a major cause of deviant behavior in all the institutions of our society. Radical social, economic and political changes, that take place in our country for more than ten years are largely the reason of social norms destroying, people began to lose orientation and all this contributes to aggressive behavior (Serikov, 2011).

Analyzing the nature of aggression it becomes clear that aggression is a sociocultural phenomenon. Aggression as a form of social behavior and aggressiveness as a personality trait are due not only to biological and psychological, but also social, historical and cultural factors in the development of society and civilization. People by nature are not aggressive, destructively oriented. Aggression is a result of social life conditions and frustration of man existential needs in modern society. Searching for these social conditions of an occurrence of aggression should be the main objective for future research.

\section{References}

Agapov, P. V. (2002). Aggression as a sociocultural phenomenon. Lomonosov readings (p. 5). M.: Moscow State University.

Agapov, P. V. (2013). Philosophical tradition of social and cultural psychoanalysis in the study of human aggression. Bulletin of Moscow State University of Culture and Arts (No. 1).

American sociology (p. 303). (1972).

Bandura, A. (2001). Social cognitive theory: An agentic perspective. Annual review of psychology, 52, 1-26. Palo Alto: Annual Reviews, Inc.

Benedict, R. (1932). Configurations of Culture in North America. American Anthropologist, 34(1). http://dx.doi.org/10.1525/aa.1932.34.1.02a00020

Billing, M. (1976). Social Psychology and Intergroup Relations.

Box, S. (1983). Power, crime and mystification. http://dx.doi.org/10.4324/9780203407752

Dollard, J., Miller, N., Mowrer, O., Sears, J., \& Sears, R. (1939). Frustration and Aggression. New Haven, CN: Yale University Press.

Freud, S. (2010). Beyond the pleasure principle. New York: bartleby.com.

Fromm, E. (1992). The anatomy of human destructiveness. New York.

Lasch, C. (1996). The Revolt of the elites: and the betrayal of Democracy. 
Lipset, S. M., \& Rokkan, S. (1967). Cleavage Structures, Party Systems and Voter Alignments. In S. M. Lipset, \& S. Rokkan (Eds.), Party Systems and Voter Alignments: Cross-National Perspectives. New York: Free Press.

Lorenz, K. (1998). Das sogenannte Böse. Zur Naturgeschichte der Aggression.

Schutz, A. (1953). Common-Sense and Scientific Interpretation of Human Action. Philosophy and phenomenological research, 14(1), 1953. http://dx.doi.org/10.2307/2104013

Serikov, A. V. (2009). Social causes of modern Russian youth aggression. Social-humanitarian knowledge (No. 11).

Serikov, A. V. (2011). Youth extremism in the South of Russia: causes of acute and preventive measures. The State and Municipal management (No. 3).

Serikov, A. V. (2013). The influence of the level of civic identity on extremization of interethnic relations in the region. Bulletin of the Russian Academy of Natural Sciences (No. 3).

Tedeschi, J., \& Felson, R. B. (1994). Violence, Aggression, and Coercive Actions.

Zillmann, D. (1971). Excitation transfer in communication-mediated aggressive behavior. Journal of Experimental Social Psychology, 7, 419-434. http://dx.doi.org/10.1016/0022-1031(71)90075-8

Zimbardo, Ph. (1973). On the ethics of intervention in human psychological research: With special reference to the Stanford prison experiment. Cognition, 2(2). http://dx.doi.org/10.1016/0010-0277(72)90014-5

\section{Copyrights}

Copyright for this article is retained by the author(s), with first publication rights granted to the journal.

This is an open-access article distributed under the terms and conditions of the Creative Commons Attribution license (http://creativecommons.org/licenses/by/3.0/). 